Lengua y Sociedad, revista de lingüística teórica y aplicada

Vol. 17, n.o 2, Lima, julio-diciembre de 2018, pp. 113-137 https://doi.org/10.15381/lengsoc.v17i2.22355

\title{
Incremento léxico del español coloquial limeño: formas y significados del vocablo «huevo» como aportes
}

\section{Lexical increase of Limeño colloquial Spanish: forms and meanings of the word «egg" as contributions}

\author{
Rómulo F. Quintanilla Anglas \\ Dpto. Acad. de Lingüística \\ CILA-FLCH-UNMSM \\ rquintanillaa@unmsm.edu.pe
}

\begin{abstract}
Resumen
Es característica inherente del ser humano su capacidad creativa. Es un ejercicio natural cotidiano y continuo que le permite encontrar solución a múltiples problemas que enfrenta en su vida diaria. Con el objeto de solucionar problemas de comunicación, por ejemplo, suele recurrir a principios como la recursividad, mecanismos como préstamos y analogías, entre otros, para formar palabras que fluyen aparentemente sin control. En el presente artículo, se describe un caso de aporte al «repertorio léxico» del español coloquial hablado en la ciudad de Lima (Perú): Se registran palabras formadas a partir del morfema lexical $\{w e b-\}$ (huev-) o del tema \{webo\}(huevo).
\end{abstract}

Palabras clave: habla coloquial, morfema, léxico, derivación, flexión.

\begin{abstract}
It is inherent characteristic of the human being his creative capacity. It is an everyday and continuous natural exercise that allows you to find solutions to multiple problems you face in your daily life. In order to solve communication problems, for example, it often resorts to principles such as recursion, mechanisms such as loans and analogies, among others, to form words that flow seemingly unchecked. This article describes a case of contribution to the «lexical repertoire» of colloquial Spanish spoken in the city of Lima (Peru): Words formed from the morpheme lexical -web- («huev»-) or the theme $\{$ webo $\}$ («egg») are recorded.
\end{abstract}

Keywords: speech, morphem, lexicon, derivation, bending. 


\section{Rómulo F. Quintanilla Anglas}

Resulta todavía fácil distinguir entre el aprender el significado de una palabra y usar la palabra una vez que ese significado se ha aprendido. Comparando esas dos actividades, es natural decir que la primera tiene que ver con aprender algo sobre el lenguaje, mientras que la segunda es típicamente aprender algo sobre el mundo.

Donald Davidson (1978; 1991; 200oc, p. 574)

\section{Introducción}

Cuando los hablantes de una determinada lengua adquieren otro sistema distinto al suyo, suelen «combinar» características gramaticales y léxicas de ambos sistemas, no solo durante el proceso, sino también cuando este ya se consumó. Ello lleva a suponer que el contacto de lenguas es un factor causal de la variación y el cambio lingüísticos. Pero el contacto de lenguas no es el único factor que subyace al proceso; a él se suman otras causas y otros mecanismos que, incluso, permitirían la «predicción» de cómo y hacia dónde se dirigen ciertas modificaciones que, en muchos casos, desembocan en cambios lingüísticos. Uno de los más comunes parece ser la analogía: proceso que consiste en la aplicación generalizada de una regla gramatical o lexical incluso en ámbitos donde «no debería aplicarse».

Los neogramáticos del siglo xix, destacaron de manera especial la función de la analogía en los cambios fonéticos como factor principal en la evolución de las lenguas, esto es, el proceso mediante el cual las lenguas pasan de un estado a otro en su estructura interna (E. Alcaraz, 1997, p. 52). Dentro del campo de la lingüística se aplica este principio para crear nuevas formas o modificar otras ya existentes, basándose en la semejanza que tienen entre sí.

Tal mecanismo no ha perdido su vigencia; en la ciudad de Lima, por ejemplo, es frecuente oír expresiones como «colabórame», «sencíllame», «yéndome», etc., usados por cierto sector de hablantes de origen migrante residentes en la ciudad de Lima. Según la gramática, son formas «incorrectas», porque el pronombre átono «me», en posición enclítica, no debe funcionar con los morfemas verbales «colaborar», «sencillar» o «ir» (gerundio). Los hablantes lo hacen por analogía con combinaciones como mírame, búscame, dame, etc. Otros ejemplos menos frecuente se observa en palabras como «amorcita», para dirigirse a una persona de género femenino (de amorcito) o como «mayora» en "esa chacra es de mi hermana la mayora»; son muestras de uso analógico que hacen del morfema de género femenino $\{-\mathrm{a}\}$.

114 Lengua y Sociedad 
Incremento léxico del español coloquial limeño: formas y significados...

El trabajo que presentamos en esta ocasión es una indagación sobre vocablos actualmente muy productivos en el habla coloquial limeño, básicamente oral. Se trata del morfema lexical \{web-\} que, flexionado y derivado, aparece en el DRAE solo en las tres formas «huevo», «huevada» $y$ «huevear» (con cinco significados). De los tres, solo «huevo» expresa el significado denotativo; en los otros casos expresan significados que no aluden ni a la forma ni al significado de este tipo.

En Lima, a partir de la primera forma se ha originado un grupo de palabras muy productivas (Almela, 1999, p. 43), básicamente en el lenguaje coloquial. Se podría decir que el morfema raíz \{web-\} y el tema \{webo-\} son «especiales», debido a que originan formas y significados léxicos que los usuarios consideran eficientes y suficientes para satisfacer sus necesidades comunicativas.

Las palabras generadas a partir de la forma «huev»o de «huevo» expresan significados connotativos más expresivos y más puntuales que las de significado denotativo. Se convierten de ese modo en efectivos auxiliares durante la comunicación, especialmente, cuando el hablante no "encuentra» las palabras estándares, esto es, con ellas soluciona su problema de comunicación.

El origen de esta versatilidad no solo es de carácter exclusivamente lingüístico; otros factores, por ejemplo de carácter sociocultural, suelen intervenir en este complejo proceso de creación léxica. Otros factores, algunos complejos, parecen confluir en tal proceso; un estudio más profundo sobre ellos podría dar luces a la relación peculiar del signo con sus usuarios: «el signo significa algo (representan algo, sirve para transmitir y recibir información) para alguien» (Dobrev y Dobreva; mencionado en Vucheva, p. 64). La complejidad de los factores sigue siendo motivo de diversas interpretaciones y de prolongadas discusiones, a pesar de que ya existen interpretaciones coincidentes entre varios autores sobre algunos supuestos. Las evitamos por el momento; pues intentarlo nos llevaría por rumbos de la semántica cognitiva, significado, designación, sentido, etc. No repetiremos discusiones como en las que se han enfrascado históricamente estudiosos: lingüistas, semantistas, semiólogos, lexicólogos, etc. Sin embargo, la observación de los conceptos mencionados siempre servirán para recordar que el «problema del significado», planteado como un problema del contenido lingüístico, es una preocupación desde mucho tiempo atrás. Solo intentamos dar cuenta de formas y significados de un conjunto de novedosas unidades léxicas, cada vez más productivas en la comunicación cotidiana.

El DRAE (Diccionario de la Real Academia Española) registra el uso de cinco significados de tres formas léxicas que provienen del morfema \{web-\}(huev-) o 
del tema \{-webo-\} ('huevo') usadas en países de Centro y Sudamérica. Las reproducimos con el objeto de tener referencia de ellas y comparar con las formas y usos semánticos que registramos en Lima (Perú).

En Chile, las formas parten de la raíz \{web-\} ('huev'-) para formar el nominal 'huevada' que significa 'asunto', 'situación' y es considerada una forma coloquial. La palabra 'huevear' (verbo) significa 'molestar'; en El Salvador y Honduras significa 'hurtar', mientras que en Chile y México, 'haraganear'. La palabra 'huevón(a)' es considerada un vulgarismo; se usa como adjetivo 'perezoso', 'tardo', 'lento', 'imbécil'; señala que en Honduras y Nicaragua, significa 'animoso, 'valiente'. La forma coloquial 'huevonada', en Colombia, Guatemala, Honduras, México y Venezuela significa 'necedad' ('dicho o hecho necio'); la palabra 'huevonear' es una forma coloquial que se usa en El Salvador, Guatemala, Honduras, México y Venezuela con el significado 'haraganear,' 'perder tiempo'; en Colombia, Honduras, México y Venezuela significa 'decir necedades', 'algo o hecho necio' (pág. 838). Como veremos más adelante, son formas y significados «mínimos» respecto a las formas y significados usados en Lima.

Dado el objetivo del artículo, nos limitaremos a señalar que una de las razones que propicia la creación de las diversas formas y significados que se deslizan a partir del mencionado morfema ( $\{$ web-\}) es la necesidad que tienen los hablantes de solucionar sus necesidades comunicativas. Para ello, recurren al sistema (lengua), al conocimiento que tienen de ella (competencia lingüística), su experiencia comunicativa y poniendo en juego su gran potencial creativo, echan mano de principios como la recursividad, la analogía, las relaciones semánticas entre palabras, etc., logran crear formas y significados distintos durante la comunicación oral. Tal fenómeno, lejos de entorpecer la convivencia, la comunicación con otros hablantes, las facilita y aun les sirve como rasgo de identificación, cohesión y de unidad como miembros de determinada comunidad de habla.

Si bien las unidades y los significados que registramos son considerados no estándares y, generalmente identificados como parte del llamado código restringido, existen algunas que por su gran productividad en el habla coloquial, hace abrigar la esperanza de que más pronto que tarde, la Real Academia Española las considerará en el DRAE; Si no todas, al menos de las más usadas.

Precisamente, el problema que se observó desde el inicio del trabajo, es el hecho que las palabras formadas a partir de «huev-» o de «huevo», son identificadas como parte del lenguaje coloquial o popular; ello propicia que no se las reconozcan y aun se las «condenen» como «vulgares» o no estándares. Tal actitud da pie a una 
Incremento léxico del español coloquial limeño: formas y significados...

aparente "glotofagia» (Calvet, 2005, p.25) de este tipo cotidiano de habla. Otra causa del poco interés por estudios lexicográficos de las mencionadas unidades es la carencia de estudios sociolingüísticos y lexicológicos sólidos que recuerden los orígenes de muchos vocablos «cultos» de hoy, y el hecho de desconocer desapasionadamente las reales limitaciones comunicativas de estudiantes: carecen de recursos léxicos durante el proceso comunicativo. Otra de las limitaciones es la carencia de sustento gráfico; no son usados en la escritura a pesar de su productividad en el uso oral.

Estas limitaciones actúan como «freno» que evita el desarrollo natural de la lengua que, justamente, se nutre del habla. Recuérdese que las lenguas naturales varían, entre otras cosas, porque tienen que dar cuenta de los cambios que ocurren en el mundo: nuevos avances científicos y tecnológicos, nuevos acontecimientos sociales, etc. En ese proceso, el incremento o la innovación léxica es una de los recursos más inmediatos que genera el hablante para satisfacer sus necesidades de comunicación. ¿Cómo son las formas de los vocablos que se generan a partir del morfema $\{$ web- $\}$, ¿cuáles son sus significados?, son preguntas a las que intentaremos dar respuestas con el presente estudio.

\section{Planteamiento del estudio}

1. Las hipótesis que orientaron este estudio fueron a) los vocablos originados a partir de la raíz $\{$ web-\} y el tema $\{$ webo $\}$ son usados, de manera frecuente, en la ciudad de Lima; b) los protagonistas de tales creaciones y usos son hablantes identificados como miembros de distintos estratos socioculturales; c) las variables sociales como la edad, sexo, educación y condición socioeconómica, solo son referenciales de la frecuencia de uso, pero no son limitantes y d) las voces creadas a partir de «huev-» o «huevo» son cada vez «más productivas» en el habla coloquial usada en ciudad limeña.

Los usuarios de las formas flexionadas y derivadas pertenecen indistintamente a diferentes grupos sociales: edad, sexo, educación, condición socioeconómica, etc. A partir del morfema \{web-,\}, inicialmente nominal (ortográficamente, «huev-»), se ha generado otras categorías y hasta composiciones como «huevoduro», unidades fraseológicas como "por las huevas». Están omnipresentes en el habla coloquial, lo cual justificaría su inclusión en el Diccionario de la Real Academia Española 
(DRAE), tal como ha venido ocurriendo históricamente en el incremento léxico expuesto en dicho documento normativo.

2. La identificación del problema de estudio se encuentra enmarcada con las características del espacio de Lima, la capital del Perú, una ciudad cosmopolita donde convergen distintos grupos de personas con sus propias formas de hablar la lengua española; muchas de estas personas provienen de distintos lugares del país y muchos son bilingües por lo cual adquirieron una variedad de español distinto al dialecto limeño y, como todo dialecto geográfico, difiere del llamado español estándar. Varias de las formas del español que «traen» los migrantes pasan a formar parte de lo que se conoce como un «dialecto o variedad» coloquial o sub estándar (para algunos «vulgar»). Es una forma de habla generalmente usada en conversaciones no formales o menos cuidadas, matizada de algunas palabras «modificadas» en sus formas y contenido semántico, aparentemente como producto del carácter bilingüe de los hablantes; sin embargo, en el lenguaje coloquial limeño existen formas coloquiales que también son usadas por hablantes limeños «nativos»; no son bilingües ni proceden de otras zonas geográfica del país.

Un grupo de palabras de uso común por un amplio sector de hablantes limeños lo constituyen los vocablos formados a partir del morfema raíz \{web-\}'huev-'y del tema \{webo\}'huevo'; lo que permite deducir que la causa de creaciones de palabras no estándares no solo es la situación de bilingüe de los hablantes (contacto), sino que en tal proceso intervendrían, además, otros factores no lingüísticos, como los de carácter sociocultural. De este modo, migrantes y nativos coinciden en el uso de un tipo de habla común básicamente oral, denominado «coloquial» (del lat. Colloquiu) «conversar»), que es el ámbito donde se usa las palabras formadas a partir del morfema aludido.

Formas y significados de palabras y de expresiones «coloquiales» (populares) suelen tener una existencia efímera; algunas son de uso más restringido y frecuente que otras, esto es, de permanencia y uso gradual. Pero en el lenguaje coloquial también hay vocablos de larga permanencia y usadas por un considerable número de hablantes; son muy productivas como recurso comunicativo. Por ejemplo, algunos de estos vocablos usados en Lima son «piña», «monse», «salado», «vaina», «misio», «chamba» y muchos otros que forman parte del acervo popular; son bastante usados en nuestro medio, sobre todo, en conversaciones amicales o informales. En ocasiones hemos encontrado que en este tipo de conversaciones los hablantes tienen dificultad en reemplazar palabras como «piña» (mala suerte), 
Incremento léxico del español coloquial limeño: formas y significados...

«monse» (mala calidad), 0 «misio» (sin dinero); incluso, algunos afirman que esas son las palabras adecuadas para expresar lo que quieren.

El caso específico que nos ocupa en esta ocasión a la descripción de algunas formas léxicas (palabras) originadas a partir de flexiones y derivaciones del morfema raíz \{web-\}, y con menor frecuencia de composiciones y como parte de unidades fraseológicas con valor léxico.. Son unidades creadas que se producen dentro del sistema y, por ello, en su estructuración se emplean los mismos procesos morfológicos utilizados para la formación de unidades léxicas reconocidas como estándares. ¿Cómo son las nuevas formas de las categorías creadas?, ¿qué proceso se ha empleado?, ¿con qué sentido se usan? Son interrogantes que se intenta responder con la presente descripción.

3. El objetivo general del presente trabajo es registrar palabras formadas a partir del morfema \{web-\}(huev-) y del tema \{webo-\} (huevo), usadas en la comunicación informal o «coloquial») por hablantes residentes en la ciudad de Lima; como objetivos específicos se señal la categoría generada, los procesos que se utilizaron en su estructuración y los contenidos semánticos más generales de cada una. Adicionalmente, con a través del trabajo se pretende llamar la atención de las autoridades académicas a fin de que algunas de las palabras, al menos de las más frecuentes, con sus significados más usados sean incluidas en el (DRAE) Diccionario de la Real Academia Española.

4. La justificación de esta investigación yace en consideraciones prácticas más que teóricas. Si bien en el presente trabajo no se discuten importantes asuntos teóricos sobre temas que conciernen al fenómeno lexicográfico: la explicación o solo la descripción, de la naturaleza de la variación y el cambio lingüísticos, la naturaleza del habla en sí, la naturaleza de hablas particulares, etcétera, el material léxico que se presenta podría constituir una valiosa fuente de datos para futuros trabajos teóricos sobre el propio tema o temas afines a la lexicografía, la lexicología, la semiótica, la semántica, etcétera.

Trabajos de esta naturaleza comprueban que el léxico es la unidad lingüística más evidente de la lengua que refleja el cúmulo de conocimientos y confirma la gran capacidad creativa de los hablantes, así como la función social que cumple la lengua.

5. El impacto social de un estudio como el presente es relativo. Estudiar hablas particulares y las unidades léxicas que las caracterizan durante el proceso comunicativo, implica lidiar con varios aspectos relacionados con el sistema mismo (gramática), con los conceptos «habla»/«hablar» y con factores que subyacen a 
estas entidades; dar cuenta de la naturaleza de factores extralingüísticos (contexto, situación) que propician la formación de particularidades léxicas (formas y significados) y con la necesidad dar cuenta de situaciones históricas, cognitivas, etcétera. Todo ello configura una compleja «unidad» que son temas de otros tipos de trabajos, pues implica universalidad (sistema), individualidad (habla), particularidad (preferencias), entre otros aspectos.

En el caso específico de la descripción que se presenta en este artículo, el interés es, básicamente, de carácter léxico-semántico de un grupo de palabras usadas como parte de un «lenguaje coloquial». De ahí que el estudio señalaría la importancia que tienen las unidades léxicas presentadas, por lo que impactaría en el sector educación, como ocurre en países como España, por ejemplo, donde muchos de los trabajos lexicográficos están direccionados hacia la enseñanza de la lengua española (Penadés, I., 2002, 2005; Penadés, I, Penadés, R. y De Oliveira, O., 2008); los resultados de la presentación impactaría también en el ámbito social por la naturaleza esencial de cotidianidad que identifica al proceso comunicativo.

En resumen, se podría señalar que el presente trabajo podría impactar en los niveles: educativo y social. En la disciplina lingüística en general y en la lexicográfica en particular (teoría y práctica). Definitivamente, se trata de una investigación de sesgo académico con carácter aplicado, dirigido a incrementar el repertorio léxico del español añadiéndole nuevas palabras con nuevas estructuras y nuevos significados, dirigidas a coadyuvar en el desenvolvimiento comunicativo, tan venido a menos, por no decir «deficiente» de niños y jóvenes, inclinados a un lenguaje «chat» o simplemente a evitar comunicaciones que impliquen el uso de mensajes «ricos» léxica y sintácticamente.

\section{Consideraciones metodológicas}

1. La población o el universo del presente estudio lo constituyeron 190 hablantes residentes en la ciudad de Lima, capital del Perú. Dentro de ellos, se consideró a diez niños mayores de diez años varones; las niñas de esa edad o menores negaron usar las formas que se les presentaba o respondían se manera evasiva, poco clara. Los niños seleccionados respondieron con mayor claridad; aunque, como se puede suponer, la referencia a la comprensión y usos de los términos presentados fueron bastante limitados en comparación con los referidos por varones y mujeres adultos. 
Incremento léxico del español coloquial limeño: formas y significados...

Después de una cuidadosa selección de informantes, el universo quedó constituido por 120 varones mayores de 20 años y 60 mujeres mayores de 20 años. Se debió distinguir entre mujeres con distintas labores: 40 estudiantes y 20 madres de familia, entre empleadas y amas de casa. Con ello, simplemente se comprobó que las palabras que se les presentó son más productivas en el sector joven. Lo mismo se comprobó en el sector de hablantes adultos: los jóvenes usan los vocablos con mayor frecuencia. No se consideró una variable específica como la educación, por ejemplo, esta fue desestimada como factor determinante, pues muchos de los vocablos referenciados, no solo son conocidos y entendidos, sino también utilizados por que, incluso, tienen educación superior. Todos los informantes residen en diferentes zonas de Lima y desempeñan distintas labores. Otra de las razones por las que no se hace mayor referencia factores socioculturales porque ello forzaría un estudio sociolingüístico; la presente descripción debe entenderse solo como lexicográfica.

Los lugares donde se hicieron la mayor parte de grabaciones fueron zonas de los distritos de San Martín de Porres, Comas, Villa El Salvador y San Juan de Lurigancho; otro bloque lo constituyen hablantes residentes en los distritos de Lince (zona próxima a la Av. Arequipa), San Isidro, Miraflores y La Molina.

2. La metodología del presente trabajo es descriptiva (cualitativa) concebida dentro de una perspectiva funcionalista. Se estructuró a partir de la principal etapa de acopio de datos. Acopio que se realizó apelando a dos formas de obtener las unidades léxicas que se estudiaron: una informal y otra formal. Mediante la primera, se procedió a grabar conversaciones espontáneas en distintos lugares de la ciudad de Lima: en las calles, tiendas o bodegas, mercados, medios de transporte masivo, prácticamente, en distintos lugar y situaciones y contextos se escuchaban relacionadas con el vocablo «huevo» [web-o], y las diversas formas y significados con los que son usados, sin distingo de edad o de sexo.

La transcripción de un primer bloque de grabaciones despertó nuestro interés por observar con más detalle los vocablos usados y suponer que las particulares formas y sentidos (significados) captados informalmente eran meritorios de ser estudiados formalmente: son frecuentes, se escuchan en diversos contextos, son empleados por hablantes sin distingo de edad ni sexo.

Considerada tal posibilidad, se transcribió un segundo bloque (otros sectores y de situaciones algo más formales). Se separaron oraciones que incluían cualquiera de las formas venidas de «web-» (huev-) y de «webo-» (huevo). Las grabaciones acordadas (más formales) fue más técnica; se grabaron conversaciones dirigidas 
(propiciaban el posible uso de ciertos vocablos), por ejemplo, se hicieron preguntas como ¿qué dicen los muchachos para indicar algo está mal hecho o es de mala calidad? Una de las respuestas fue «está hasta las huevas». La duda inicial fue si se consideraría solo «huevas» o la unidad fraseológica «hasta las huevas». Ello dio pie a la observación, no considerada inicialmente, de «unidades fraseológicas» y de «composiciones» que incluyen formas venidas del morfema o tema mencionados.

El material lingüístico recogido a través de ambas modalidades permitió elaborar un cuestionario ad-hoc mínimo, que incluía preguntas directas, más adelante ampliado conforme se avanzaba con entrevistas personales, individuales y grupales.

Las primeras observaciones de hallazgos iniciales dejaron en claro que nuestra inicial suposición de que la variable social «edad» de los usuarios de las formas venidas de «huevo» (flexionadas y derivadas) era errada, pues la gran variedad de términos relacionados con la raíz $\{$ we- $\}$ y el tema $\{$ webo- $\}$ no eran de uso privativo del «lenguaje juvenil». Igualmente, se fue observando detalles como que las variables «origen» $\mathrm{y}$ «situación socioeconómica» tampoco eran determinantes en la creación de las formas usadas por hablantes residentes en Lima, solo marcaban la diferencia respecto a la frecuencia y situación en que se usan.

El cuestionario aplicado a los informantes pretendía obtener cuatro datos fundamentales: ¿Conoce la palabra? 2. ¿Qué significa? 3. ¿La usa?, 4. ¿Qué otro significado tiene? Como se ve, la cuarta pregunta buscaba el aporte del hablante. El cuestionario aplicado que permitió corroborar y obtener importantes datos tiene el siguiente formato:

\section{Cuestionario}

1. Ese tipo habla por las huevas.

¿Conoce la frase subrayada?

¿La usa?

¿Qué significa palabra subrayada?

a. que habla sin razón.

b. que habla tonterías.

c. que habla por gusto.

¿Qué otro significado tiene?

d. 
Incremento léxico del español coloquial limeño: formas y significados...

Adicionalmente, se hizo la siguiente pregunta:

¿Cuándo o en qué circunstancia la usa? Puede marcar más de una opción.
a. Con mis amigos
b. Con mi familia
c. En cualquier lugar y momento
d. Cuando estoy molesto

Otra forma usada para captar más formaciones a partir de \{web-\} fue preguntar: ¿Conoce usted otras palabras que se relacionen con «huev o huevo»? Los aportes significantes salieron mayormente de boca de jóvenes de entre 20-25 años.

En ocasiones, algunos de los encuestados no siempre aceptaban utilizar el término o algunas de sus variantes presentadas (profesionales o damas mayores); se debió recurrir constantemente a las grabaciones espontáneas obtenidas en misma zona donde residían. Igualmente ocurrió para obtener datos sobre las circunstancias en que se usa uno u otro vocablo.

Las variables de edad, el sexo, educación, condición socioeconómica, solo fueron considerados como referencias para entender las frecuencia con que se usan. Son de carácter sociolingüístico y el trabajo es más lexicográfico. Un dato que consideramos no marginal, y que sirvió para ampliar el ámbito de usuarios femeninos, fue la edad de mujeres adultas; varias de ellas superaban los cincuenta años y más de una declaró que tal palabra relacionada con «huevo» era la correcta (culta o estándar).

Las entrevistas personales sirvieron para constatar que la serie de palabras flexionadas o derivadas a partir de «huev-» o de «huevo» (derivadas y flexionadas) son muy productivas en la variedad de habla coloquial, básicamente oral.

\section{Resultados}

Generalmente, cuando los hablantes nombran o etiquetan cosas, hechos o algún acontecimiento que rodean sus vivencias toman como referentes la formas que tiene o las funciones que cumple el elemento nombrado; por ejemplo, la palabra del 
español «rompe muelle» es un compuesto que hace referencia o alude a la función que esta elevación o montículo cumple: «aminorar la velocidad para no romper los muelles del vehículo». Hace algunos años, observamos a los costados de la carretera que nos llevaba a la Ciudad Universitaria de la Universidad Nacional de Cajamarca, algunos avisos preventivos que decían «Cuidado, camellones a 500 metros», al costado, otros que decían: "Cuidado, gibas a 500 metros», significan lo mismo a través de formas distintas: «camellones» $\mathrm{y}$ «gibas»; lo que es obvio es que mientras los «limeños» aluden a la función, los cajamarquinos lo hacen a la forma, que alude al abultamiento a la «joroba» del camello o y de sus gibas).

La muestra general reunida a partir de [web-] en muchos casos alude al significado denotativo de la forma «huevo», hace alusión al concepto de «masculinidad» en el nivel de la categoría [+humano], pero hace alusión a «femenino» en el nivel de la categoría [+animal] (ave hembra). Al respecto, en el Diccionario de la Real Academia Española (DRAE), dice de huevo: «(del latín ovum). Cuerpo redondeado, de tamaño y dureza variables, que producen las hembras de las aves o de otras especies animales, y que contiene el germen del embrión y las sustancias destinadas a su nutrición durante la incubación» (2001, p. 838).

En la mayoría de casos, las palabras generadas a partir del morfema aludido, se caracterizan por contener significados connotativos. Veamos un ejemplo preliminar extraído de un corto diálogo. Las protagonistas son dos señoras madres de familia (de 42 y 55 años). Una de ellas expresaba su molestia y lamento al mismo tiempo, por algo que su hijo había hecho, la amiga la entendía claramente (muestra que también conocía y usaba las palabras que señalamos en negrita) de modo que nunca se bloqueó la comunicación:

A: La verdad que no entiendo; por qué te ocurre eso.

B: La culpa es mía. Todo le daba; a veces a escondidas de su padre.

A: ¿Qué tendrán en la cabeza estos huevones?

B: No sé. Ya ves... tanta huevada, ¿para qué?

A: Sí, pues, mira la huevada que te hace ese huevón de tu hijo.

A: ¿Y su padre qué dice?

B: Ese es otro huevoduro; ni siquiera lo molestó. Sus palabras fueron: «Qué vamos hacer, ya está hecha la cosa». 
Incremento léxico del español coloquial limeño: formas y significados...

Categorías

«huevada» $\rightarrow$ nombre o sustantivo.

«huevón», «huevones» $\rightarrow$ adjetivo

«huevo-duro» $\rightarrow$ adjetivo (compuesto) significados

'tontería,' 'necedad'

'tonto', lerdo', 'bruto'

'lento', 'falto de carácter'

Obsérvese que la forma derivada «huevada» es la misma usada en otros lugares como en chile; la diferencia es semántica: en Lima significa 'tontería', 'cosa o hecho de poco valor o de poca importancia'; en Chile, significa solo «asunto» o «situación».

\subsection{Lenguaje coloquial}

No es muy clara la definición de lenguaje coloquial. Suele entenderse por oposición a lenguaje formal o correcto. Muchos autores llaman registro coloquial al empleo del lenguaje en un contexto de comunicación informal, esto es, familiar. Dado que la voz coloquio es sinónimo de conversación, bien podría entenderse que el lenguaje coloquial es el lenguaje de la cotidianidad. Es decir, el lenguaje que es independientemente de la profesión o del estatus social del hablante, se le utiliza en la intercomunicación natural y diaria, que se caracteriza por ser espontánea, relajada y emotiva, claramente expresiva. Aunque sus unidades y reglas combinatorias se producen respetando el sistema, muchas de sus unidades léxicas (o palabras) aún son consideradas incorrectas por la norma.

Es la forma cotidiana de expresar la lengua a través de hablas poco convencionales, simples, no sofisticadas, aunque siempre ceñido al sistema, en nuestro caso, a la gramática del castellano o español. El fenómeno de variación y cambio lingüísticos no es muestra de deficiencias lingüísticas ni culturales; son procesos sistemáticos y lícitos que proporciona el sistema para una comunicación inmediata y directa entre interlocutores.

Ya Werner Beinhauer (1963 [1958], p. 9) describía al lenguaje coloquial como un hecho de naturaleza espontánea y que brota en la conversación diaria. A manera de queja, señalaba que la tendencia de los estudios lingüísticos aspira, casi exclusivamente, a estudiar y a enseñar la lengua literaria. Es un error-señalaba el autorconfundir el lenguaje cotidiano que se habla, con la lengua también cotidiana, pero escrita o impresa. Al tratar de lenguaje coloquial nos referimos-decía Beinhauerúnicamente a la lengua viva conversacional. Sus medios expresivos no constan 


\section{Rómulo F. Quintanilla Anglas}

solamente de elementos sintáctico-estilísticos y de elementos lexicológicos, pues a todos ellos se agregan los medios dinámicos de entonación, gestos y mímicas.

Claramente el autor hace referencia a lo que se conoce como reforzadores de la comunicación verbal, esto es, a la comunicación no verbal tanto visual como auditiva.

En otro pasaje de su disertación, Beinhauer señala que, generalmente, se olvida que la lengua, incluso de escritores y poetas, está arraigada profundamente en el subsuelo del lenguaje familiar y popular, del que se nutre a diario. Por tanto-señala-, que solo será capaz de sentir, captar y apreciar las últimas intenciones y exquisiteces, incluso de un lenguaje artístico [muy elaborado], quien conozca también la materia prima del que este está amasado, o sea, la lengua del pueblo. Es más-señala- no me recato en afirmar que quien no está debidamente familiarizado con el lenguaje coloquial, tampoco puede dominar realmente la lengua escrita.

Con otras palabras, señala que es necesario el estudio teórico de la lengua, ¡Qué duda cabe! -afirma- pero la posibilidad de manejar bien una lengua no se desenvuelve solo en los «eriales» de lo puramente teórico.

Ludwig Wittgenstein (1988 [1958], p. 86) en su obra Investigaciones filosóficas, cambia su posición inicial (de veinte años atrás) respecto a la lengua; en la mencionada obra señala que la lengua cumple múltiples funciones, que es un instrumento que puede ser usado para diversas actividades: describir, dar órdenes, hacer promesas, inventar historias, contar chistes; llama a estas actividades «juegos del lenguaje». Con ello desea señalar que el lenguaje siempre se emplea en un entorno social, como instrumento de participación en la actividad común. Sostiene una concepción pragmática del lenguaje, pues concibe que el lenguaje se crea y recrea en esa actividad común.

Ahora, según L. Wittgenstein, el significado de las palabras no se reduce a nombrar objetos, sino que el significado se identifica con el uso de las palabras en cada juego del lenguaje. Aprender el significado de un término no supone solo aprender el objeto que el término denota, sino aprender a usarlo en su contexto lingüístico. El lenguaje es una forma de vida y las palabras forman parte de la acción humana; su significado dependerá de las reglas que dominen su uso, y estas reglas se fijan en el contexto lingüístico y práctico de esa actividad. ${ }^{1}$

Adaptado, en parte, de la presentación que Manuel Pérez Cornejo hace de Wittgenstein. Madrid, 2013. 
Incremento léxico del español coloquial limeño: formas y significados...

Se observa, pues que los usos de unidades lingüísticas como las palabras comúnmente presentan continuas novedades semánticas, muchas veces originadas por contextos y situaciones de comunicación. Ello parecería confirmar aquello de que solo la competencia lingüística es sistemática (Chomsky, 1957) y meritoria de ser estudiada como único objeto de investigación de la lingüística. Pero tal suposición parece haber perdido peso en los últimos años debido a la publicación de estudios sistemáticos de carácter sociolingüístico, pragmático, etc. En los que se muestra la sistematicidad de las hablas. Así visto el fenómeno que nos ocupa, en el presente estudio nos acercamos más a Wittgenstein y no al formalismo que se atrinchera en cuidar solo los significados fijos, despojados de aspectos sociales, culturales e históricos.

\subsection{Significado}

No se puede perder de vista que los hablantes organizan unidades lingüísticas, desde las mínimas (fonemas) hasta las mayores de carácter léxico, sintáctico (morfemas, palabras, frases, oraciones, etc.) que, además de conformar estructuras, contienen significados (o sentidos) o participan en dotarlas, pues es a través de significados que se intercomunican en una determinada comunidad.

El significado es una abstracción o una imagen mental que los hablantes conciben a través del significante, que es su soporte material. Es, pues, la asociación significante-significado que estructuran signos lingüísticos, para muchos, el más versátil, el más grande logro de la creación humana.

El significado que posee una palabra o una expresión puede ser denotativo o connotativo. La primera clase de significado es considerado el básico, principal, el significado lógico de una palabra, por ello, se le reconoce también como el significado objetivo, de carácter universal, ajeno a cualquier contexto social, geográfico, cultural, etc., es compartido por una mayor cantidad de personas y visto como parte de hablas estándares.

El significado connotativo suele ser de carácter subjetivo y se da, básicamente, en el nivel de las hablas; no siempre aparecen registrados en el diccionario oficial. Así, por ejemplo, el significado denotativo de la palabra 'paloma' reza en el DRAE (2001, p. 1126), Como «Ave domesticada que provino de la paloma silvestre y de la que hay muchas variedades o castas, que se diferencian principalmente por el tamaño o el color». 


\section{Rómulo F. Quintanilla Anglas}

Un significado connotativo de 'paloma' que registra el DRAE, en la misma página, es «Persona de genio apacible quieto». Sin duda hace alusión a la pasividad de la paloma. En el habla coloquial suele usarse también con otros sentidos: «mujer», «mansedumbre», «delicadeza», etc.

El sentido está vinculado al entendimiento o a la razón. Puede tratarse de un modo particular de entender algo, pues el sentido suele estar vinculado con las situaciones de comunicación.

Es bastante aceptado que, en el proceso de comunicación, tanto el contexto (lingüístico) como la situación (extralingüístico), son factores que influyen en la precisión de significados y sentidos de unidades léxicas. Imaginemos el uso que hacen distintos grupos de hablantes del vocablo «operación».

El jefe militar informa que fue un éxito la operación realizada por la tropa; el médico por su parte da cuenta de que la operación de trasplante de corazón duró seis horas; el ingeniero no quiere quedarse callado y señala que la operación realizada permitió calcular el peso que resistiría el puente construido; el término polisémico se presta a ser utilizado hasta por hablantes de «sectores informales», por ejemplo, no sería nada raro escuchar a un grupo de asaltantes que planifican el asalto de a un bancos decir: «La operación tiene que ser perfecta si no queremos ser atrapados»

Se puede entender que la palabra operación es usada con distintos significados en situaciones contextuales específicos, aun cuando se puede abstraer un significado general que subyace a todos ellos: «acción planificada».

Una de las características que se atribuye al signo lingüístico es su naturaleza «arbitraria». Para F. de Saussure (1945, p. 129), el signo lingüístico es una entidad psíquica de dos caras: un concepto y una imagen acústica, que están íntimamente unidos y se reclaman recíprocamente. Posee dos aspectos: la arbitrariedad y la linealidad. El primero se refiere a la no existencia de relación directa entre signo lingüístico y su referente o realidad extralingüística. La arbitrariedad afecta tanto al significante como al significado, ya que las relaciones entre uno y otro no son lógicas ni relacionales, ni poseen motivación intrínseca, y se deben a las convenciones creadas a la tradición y uso (Alcaraz y Martínez, 2004). 
Incremento léxico del español coloquial limeño: formas y significados...

\section{Resultados}

Considerando los conceptos y criterios básicos anteriores, a continuación, se presenta y analiza un conjunto de palabras formadas a partir del morfema lexical \{web-\}(huev-) y del tema \{webo\}(huevo). Se describe el proceso utilizado en la formación de la palabra y los contenidos semánticos con los cuales los usan.

Descripción del diálogo entre dos mujeres adultas (pp. 11-12). Se observa:

1. En primer lugar, se observa que existe el diálogo, nunca este se bloqueó. Ello muestra que ambas conocen los significados de los términos.

2. La palabra «huevada» no hacen alusión ni a la forma oval que presenta el huevo (de las gallinas) ni a la función (alimento).

3. El lexema $\{$ web- $\}$ se deriva añadiéndole el morfema $\{$-ad- $\}$ y se flexiona mediante el morfema de género femenino $\{-\mathrm{a}\}$. El morfema derivativo le asigna el rasgo [más adjetivo], que es el valor que suele adquirir los verbos de forma no personal o verboide participio, como en 'usar' > 'us-ad-o', 'com-id-o, etc.

4. Según las circunstancias de comunicación, el término 'huevada' tiene el significado de 'cosa' en «tanta huevada», pero en este contexto también significa 'atención solícita, bondadosa, 'comodidad', 'preferencias', algo positivo. El mismo término en «mira la huevada que hace», tiene un significado relacionado con "cosa o hecho negativo» (inadecuado); son significados subjetivos, (adjetivos explicativos). Los significados con que se usa no tiene relación con la forma ni con el significado denotativo del vocablo 'huevo'.

La señora (madre que se queja) dijo que había hecho estudiar a su hijo mayor en un colegio particular, que lo matriculó para estudiar inglés en un instituto; el joven ingresó a la U. Católica y al año siguiente, contrajo matrimonio civil con una de sus compañeras de estudio. Dijo, además, que ahora su hijo está viviendo en casa de sus suegros y trabaja como cajero en un supermercado.

El término 'huevoduro' es una palabra compuesta que, según el contexto, tiene un rasgo atenuante, si se quiere, menos peyorativo que huevón: «Eres un huevón, ¿Cómo vas a pagar doscientos soles por esa camisa?» Por supuesto que el morfema \{-on\} de aumentativo es el que está marcando el concepto peyorativo en un grado mayor. En el diálogo, «huevoduro», que califica al padre, se entiende como 'pasivo', 'falto de carácter'-según indicó la señora. 


\section{Rómulo F. Quintanilla Anglas}

\subsection{Descripción}

Se registra una relación de palabras formadas a partir del morfema \{web-\}. En la escritura se usan las formas gráficas «huev-», flexiones y derivaciones. Por tratarse de un artículo, la descripción exige brevedad, exenta de muchos detalles, pero sin descuidar la objetividad, pues, el objetivo del trabajo es registrar usos colectivos no personales o individuales.

1. «Ese tipo tiene un huevo de plata».

Adverbio; palabra donde el morfema flexivo 'masculino' \{-o\}del español se ha fusionado a la raíz de origen: huev- y dado «huevo» con el concepto de 'gran cantidad'. En algunos contextos es menos usual o menos aceptados, que en otros, por ejemplo, en «Ese tipo tiene un huevo de casas», lo entienden, pero se usa poco. No se considera una combinación adecuada al sentido que el hablante le da; sí lo es la combinación «Tengo un huevo de problemas en la cabeza».

2. «Este problema está huevo».

Adjetivo formado como en el caso anterior. En este contexto, 'huevo' equivale semánticamente a 'fácil', 'sencillo'. Una vez más el contexto es fundamental, porque no podría decirse * «esta puerta está huevo».

En «el examen estaba huevito», el morfema diminutivo $\{-i t\}$ aumenta el nivel de facilidad, disminuye la dificultad, esto es, equivale a 'muy fácil' («facilito»). Aparentemente contradictorio es el significado de la forma «huevazo» que también significa 'muy fácil', 'demasiado fácil’: «¿Qué tal la prueba? ¡Huevazo!»; se observa que tanto el morfema $\{$-it $\}$ 'diminutivo' como el aumentativo $\{$-aso- $\}$ (-az) «aumentan el concepto de 'fácil'; ello no ocurre en otras combinación como «huevonazo», donde el morfema aumentativo cumple su función.

3. «Tienen que poner huevos para ganar. Le puso huevo, por eso ganó».

Expresiones en las que, tanto la forma plural «huevos» como el singular «huevo» expresan el significado de 'energía,' 'valor', 'voluntad'. Parece ser que solo en este significado hace alusión a una parte del significado «original» de la palabra: no a la forma, sino a la función 'nutritiva' (da enegía). 
Incremento léxico del español coloquial limeño: formas y significados...

4. «Nunca entendí esa huevada».

Huevada: [web-ada]. Palabra formada añadiendo a la raíz el morfema derivativo $\{$-ada\} que convierte al lexema nominal [web-] en el participio con valor adjetivo; el morfema $\{-a\}$ está fusionado a la raíz, no funciona como femenino. Significa «algo sin valor», «sin importancia». Algunos informantes señalaron que tal palabra se utiliza para referirse a algo de manera despectiva «Esa huevada no vale tanto». Suponen que 'huevada' [+adjetivo] es cualquier cosa de bajo valor o mal elaborada; También se usa en plural: Pelean por huevadas.

5. «Este huevón no trajo la plata para pagar».

Adjetivo. A la raíz «huev-» se ha añadido el aumentativo - on para dar la forma «huevón» que también funciona pluralizada. Equivale a 'tonto,' 'ingenuo', 'despistado' o 'distraído'. El morfema \{-on\} 'aumentativo' funciona rasgo superlativo: 'muy tonto'. «tontísimo».

6. «Este ha venido solo a huevear».

Huevear: verbo formado con la raíz «huev-» al cual se le añade el morfema verbal derivativo -ear, Se usa por analogía, como en 'hojear' (de hoja), 'ojear' (de ojo). Es usado con el significado 'dejar pasar el tiempo sin hacer nada productivo'. En la forma de gerundio tiene otro significado. El participio «hueveando», en expresiones como: - ¡Ya se levantó la cuarentena! - «Entonces ya estamos hueveando» se usa con el sentido 'hacer algo sin motivo, sin razón', 'perdiendo el tiempo'. En contextos como «Nos está hueveando», el sentido con que se usa es 'engañando', 'haciendo pasar por tonto o por ingenuo'.

7. «Este nos está hueveando hace tiempo».

Este gerundio del verbo 'huevear' se usa con el sentido de 'engaño', 'hacer pasar por tonto a alguien', 'prometer sin sustento'.

8. «No trabaja, para hueveando en el barrio».

En este contexto, 'hueveando' tiene el sentido de 'disimulo', 'holgazanería', 'fingimiento'. Viene a huevear: 'fingir que hace algo productivo', que 'trabaja'. No trabaja, huevea. 


\section{Rómulo F. Quintanilla Anglas}

9. «Es un tipo ahuevado».

Adjetivo. La palabra «ahuevad(a)» está formada por parasíntesis: a + huev-ad-o. Significa 'distraído', 'atontado,' 'lento de reacción', etc. También funciona como atributo: hoy Tito está (medio) ahuevado, está «atontado», «torpe».

10. «Pusieron huevos y ganaron, eso fue todo».

Sustantivo. Término venido del original argot deportivo. Significa 'fuerza', 'voluntad', 'empeño'.

11. «Camina pisando huevo».

En este contexto «huevo» forma parte de la unidad fraseológica "pisando huevos»; las unidades simples y la colocación que la estructuran no son modificables. Significa 'delicadeza fingida', 'finura forzada'.

12. «Este es un huevofrito».

Adjetivo. Es una palabra compuesta con matiz eufemístico atenuante de 'tonto', 'ingenuo', no es despectivo. Parecería que en este caso se alude a la forma «aplanado» $\mathrm{o}$ «aplastado psicológicamente».

13. «No seas huevinche».

Adjetivo. Si en el caso anterior, el compuesto era una forma atenuante de «tonto», este derivado «huevinche», además de la connotación atenuada, le añade el rasgo «afectivo», no tiene carácter peyorativo: 'ingenuo, 'distraído'. Es un trato casi familiar, eufemístico.

14. «iEste hueveras derramó la pintura!».Adjetivo. Palabra derivada a partir de huev-, equivale a' tonto', 'distraído'. A diferencia de la forma anterior, esta no expresa rasgo menos «afectivo». Algunos informantes jóvenes dijeron que la usan en forma interjectiva, con un matiz de "pensamiento disperso», «sin remedio» como cuando se corta una huevera y todo se desparrama: «este huevera es más olvidadizo...». 
Incremento léxico del español coloquial limeño: formas y significados...

16. «Es un huevonazo, no hizo nada por escaparse».

Adjetivo. La estructura de esta palabra es 'huev- + dos morfema gramaticales de aumentativo: $\{-o n\}$ que daría 'huevón' y $\{-$ as- $\}$ ('az-'), que formaría 'huevonazo; tiene el significado superlativo de 'muy tonto' o de 'muy distraído'. Como se vio, en «huevazo» el aumentativo $\{\{a z-\}$ cumple una función contraria 'muy fácil', 'facilísimo'. En contextos como «Es una huevadaza de mujer», el morfema 'az' funciona como «afectivo-aumentativo» «muy bien proporcionada y muy hermosa». «huevoncito», a pesar que incluye el $\{$-it-\}'diminutivo' tiene el rasgo peyorativo «tonto» + «débil», «incapaz».

17. «Dice puras huevadas».

Sustantivo. Se supondría que el morfema $\{$-ad- $\}$ marca participio de verbo, que funciona como adjetivo; sin embargo se utiliza como sustantivo con función sintáctica de objeto directo: dice eso (lo dice): 'banalidades', 'cosas impropias o fuera de lugar'.

18. «Esta huevada es pan comido».

Sustantivo. «huevada» también se usa como sustantivo. Como en el ejemplo, puede estar seguida de formas simples «esta huevada pesa», o por una frase hecha en función de atributo como el ejemplo (frase hecha "pan comido»). Significa "cosa», no necesariamente con carácter peyorativo, simplemente significa "cosa», como muletilla o comodín que reemplaza a cualquier palabra que se olvida en el momento: «No me acuerdo dónde dejé esa huevada». «Dijo una huevada que no entendì».

19. «Oye, huevas, te dije solo un poco, le pusiste mucho cemento».

Adjetivo. Se usa para calificar a personas de 'tonto, 'distraído', pero con un trato más amical. La forma «hueva-s» se refiere a persona; no puede ser «huevos»y significar lo que se desea. Se puede decir que el tema «huevo» es la base formal de la palabra donde «-s» sigue cumpliendo su valor de 'segundas persona'. También se usa como adjetivo la palabra «huevonada» en contextos como «Todo eso es una huevonada» para señalar un «huevada» mayor (rasgo + colectivo). 


\section{Rómulo F. Quintanilla Anglas}

20. «Hicimos todo por las huevas, nadie vino».

Sustantivo. «huevas», derivado que forma parte de una unidad fraseológica «por las huevas». Se usa con el significado de 'en vano,' 'por gusto', sin beneficio o sin resultados positivos.

21. «Después de la pelea, quedó hasta las huevas»

Adjetivo, También como parte de unan unidad fraseológica «hasta las huevas», esta forma significa 'cansado,' 'maltratado', 'extenuado', 'en malas condiciones'. En algunos casos, también se usa para expresar la idea de 'disminuido psicológicamente’: «después del examen que dio, quedó hasta las huevas; no celebrará su cumpleaños».

22. «No seas huamán, eso era antes, ahora ya no tienen tubos, todos son televisores digitales».

Adjetivo. A pesar que la forma «huamán» no deriva de «huev-» o de «huevo», el significado 'tonto,' 'lento,' 'ingenuo' lo identifica como sinónimo de forma eufemística de 'huevón. Podría ser que el referente es solo la forma gráfica inicial: hue-von / hua-mán.

\section{Discusión}

Relacionados con trabajos lexicográficos del española peruano, se han publicado artículos, relaciones y aun diccionarios de Peruanismos. Ellos han demandado grandes esfuerzos en distintos niveles. El objetivo, coincidente en la mayoría de los casos, ha sido describir la realidad lingüística peruana respecto a la lengua oficial: el español. No faltan propósitos alturados, y por ello, plausibles, que los autores declaran coronar con sus trabajos. Por ejemplo, en el artículo que publican Falla, J. y Sancho, Ma. (2013) «Las variedades del español en el Perú. Un estudio desde la dialectología» se señala que trabajos como el mencionado, pretenden revitalizar las lenguas indígenas, dado el riesgo de su extinción y que con ello se pretende salvaguardar el patrimonio lingüístico y cultural de América. Y el artículo trata aspectos del español, que por supuesto no es una lengua «indígena» de América. Al margen de esa duda, los autores mencionan a especialistas como J. Lipski, Germán de Granda, Rocío Caravedo, etc., autores que desarrollan aspectos 
Incremento léxico del español coloquial limeño: formas y significados...

del español andino, como lo hacen también Cerrón-Palomino, Gladys Merma y otros. Ellos aluden, básicamente, a aspectos fonético-fonológicos y sintácticos.

La búsqueda de trabajos relacionados con las palabras que presentamos ha sido prácticamente infructuosa; es posible que la causa esté relacionado con criterios como «mala palabra», «lisura», «altisonante», «disfemismo», «tabú lingüístico», que no harían sino poner más peso sobre la lápida que cubre formas de lengua viva que pugnan por ser reconocidas como nutrientes del sistema. Con prejuicios subjetivos no se logra mantener una «lengua pura».

Werner Beinhauer (1958 [1963], p. 11) dice: «Cuando se trata de indagar la vida de un idioma, no hay que andarse con escrúpulos en la elección del material analizable». En ese sentido, el material presentado no es una descripción básicamente gramatical, más bien manifiesta cierta disposición psicológica, considerando que la «lengua hablada» de ninguna manera es ajena a la comunidad, pues ella refleja el carácter idiosincrásico de la lengua, la clave de la esencia social. No se desconoce que los principios, los supuestos, las deducciones son necesarios para captar, elaborar y justificar teorías sobre formas y significados encasillados herméticamente, y que son puestos en práctica para estudiar el sistema de un modo inmanente. Pero ello no debe minimizar la importancia de darle cabida al pueblo para que «hable con libertad».

Los usos que se hace del término en cuestión (sus flexiones y derivaciones) son tan frecuentes, cubren amplios espacios la nuestra ciudad y es usado por un amplio sector social de hablantes, que bien podría esperarse que la RAE, más pronto que después, incluya varias de estas formas y significados en el Diccionario de la real Academia Española (DRAE). Recuérdese que es el uso un factor de mucho peso para propiciar tal decisión.

En lo que respecta a la relación de vocablos registrados, podemos decir que cada unidad léxica es un signo lingüístico; el carácter «arbitrario» (pág. 16) que se le atribuye parece ser gradual dependiendo de cada unidad léxica. Así, por ejemplo, parecería que el compuesto «huevo duro» es menos arbitrario que «huevada» debido que es más claro para la imaginación del hablante asociar «duro» con «piedra» cuya connotación sería «duro como una 'piedra' para 'pensar,' 'reaccionar,' 'decidir correctamente', es decir, además de 'tonto' (huevón) se le añade el matiz 'incapaz de pensar'. Con «huevada» no ocurre lo mismo; en principio porque el hablante supone que el contexto propiciará la comprensión de su interlocutor, debida cuenta que «el signo no es signo por sí mismo, sino porque la función de la designación le es asignada por la conciencia pensante en 


\section{Rómulo F. Quintanilla Anglas}

el proceso de interacción práctica con el mundo, con vista a la comunicación y a la cognición en la sociedad» (E. Vucheva, 2016, p. 64). Desde esa perspectiva, la designación sería una operación sígnica de categorización la realidad extralingüística que utiliza el sistema de signos (los significados en cuanto conceptos, esto es, en su función sígnica) establecidos en cada comunidad lingüística para los objetivos de la comunicación.

De modo que el significante de cada vocablo hace referencia a conceptos (que remiten a la realidad), «huevo frito» hacer referencia a «algo plano, aplastado, chato» (imagen de un huevo frito): además de 'tonto' (huevón) se suma otro rasgo «que no destaca», «no sobresale».

\section{CONCLUSIONES}

Podemos concluir señalando que la lengua es un fenómeno social que se mueve al ritmo de los eventos sociales. Que tiene que adecuarse constantemente a la realidad móvil y cambiante de la época, para satisfacer las necesidades comunicativas de los hablantes que están en continua y constante interrelación.

Las hablas y sus unidades léxicas son creaciones basadas en el conocimiento del sistema, la capacidad creativa y experiencia de los hablantes de unas comunidades de habla que se identifican por hablar una lengua misma con diversos matices, que comparten otros conocimientos además de los lingüísticos.

Si bien lengua y habla constituyen una unidad humana, no constituyen una identidad, como dijera Lev S. Vygotski (1934, p. 406) cuando comparaba unidades de pensamiento con unidades de habla.

Los vocablos presentados, cuyos sentidos dependen de contextos y situaciones de comunicación, son cada vez más utilizados por hablantes sin distingo de edad, género o situación socioeconómica; tales variables sociales suelen ser referenciales para determinar la frecuencia y situación de uso de los vocablos descritos.

Concluimos con la transcripción de un atinado comentario del profesor Alejandro Fajardo Aguirre (2010):

Como conclusión de alcance más general, consideraremos que la lexicografía del español de América ha alcanzado un grado de madurez que obliga a la española, al diálogo con las demás Academias, a redefinir con claridad la función y la naturaleza del DRAE. La aparición del DA [Diccionario de Americanismos], sustentada por los trabajos previos de lexicógrafos de muchos lugares del mundo, producirá, 
Incremento léxico del español coloquial limeño: formas y significados...

sin duda, una revolución que no solo cambiará la lexicografía general, sino que obligará a todos a ahondar en la política lingüística panhispánica y a redimir la norma léxica del español actual. (p. 333)

\section{Bibliografía}

Alcaraz, E., \& Martínez, Ma. (2004). Diccionario de lingüística moderna. Barcelona: Ariel.

Almela, R. (1999). Procedimientos de formación de palabras en español. Barcelona: Ariel.

Beinhauer, W. ([1958]1963). El español coloquial. Madrid: Gredos.

Calvet, L.-J. (2005). Lingüística y colonialismo. Breve tratado de glotofagia. Argentina: Fondo de Cultura económica

Charaudeau, P., \& Maingueneau, D. (2005). Diccionario de análisis del discurso. Buenos Aires: Amorrortu.

Drae. (2201). Diccionario de la Real Academia Española. Madrid: Asociación de Academias de la Lengua Española.

Fajardo, A. (2010). Capítulo 7. La Lexicografía del Español de América. En Aleza, M., \& Enguita, M. (Coords.), La lengua española en América: normas y usos actuales. Valencia: Universidad de Valencia. Recuperado de https://www.uv.es/ aleza/cap.\%207.\%20ea\%2olexicog\%2oprim\%2opart.pdf

Falla, J., \& Sancho, Ma. A. (2013). Las variedades del español de Perú. Un estudio desde la dialectología. Revista Nuevo Humanismo, 1(1). https://doi. org/10.15359/rnh.1-1.3

Penadés, I. (2002) Diccionario de locuciones verbales para la enseñanza del español. Madrid: Arco Libros.

Penadés, I. (2005). Diccionario de locuciones adverbiales para la enseñanza del español. Madrid: Arco Libros.

Penadés, I., Penadés, R., \& Oliveira, X. de. (2008). 70 Refranes para la enseñanza del español. Madrid: Arco/Libros.

Vigotsky, L. ([1934] 1995). Lenguaje y pensamiento. Barcelona: Paidós.

Vucheva, E. (2016). Un modelo integral del hablar. Niveles, unidades y categorías. Hacia la lingüística del hablar. Valencia: Tirant lo Blanch.

Wittgenstein, L. ([1958], 1988). Investigaciones filosóficas. Barcelona: Paidós. 